\title{
Penerapan Model ADDIE dalam Pengembangan Media Pembelajaran di SMPN 22 Kota Samarinda
}

\author{
Andi Rustandi ${ }^{1}$, Rismayanti ${ }^{2}$ \\ ${ }^{1}$ Program Studi Pendidikan Komputer, Fakultas Keguruan dan Ilmu Pendidikan, Universitas Mulawarman \\ ${ }^{2}$ Program Studi Pendidikan Komputer, Fakultas Keguruan dan Ilmu Pendidikan, Universitas Mulawarman \\ ${ }^{1}$ andi.rustandi@unmul.ac.id, ${ }^{2}$ ririsma056@gmail.com*
}

\begin{abstract}
The type of research used Research and Development $(R \& D)$ with a ADDIE development model consisting of five stages, namely Analysis, Design, Development Implementation and Evaluation. At the analysis stage, a literature study and field study, producing the media by making flowcharts and storyboards, Develop the media according to the design that had been made. The final stage is an evaluation where the media is validated by the subject teacher as a material expert and 3 media validation experts to see the feasibility of the media. The results of the research and development of this learning media were developed with a ADDIE (Analysis, Design, Development Implementation and Evaluation) development model with data collection techniques for field studies, literature studies and questionnaires that were analyzed descriptively by media experts. It was stated that this learning media was "very feasible" to be used use with a percentage of $90 \%$ eligibility and a percentage of 91\% eligibility by material expert was declared "very feasible"
\end{abstract}

Keywords : Media Learning , ADDIE, Algebraic Count Operations, Math

\begin{abstract}
Abstrak
Jenis penelitian yang digunakan adalah Research and Development $(R \& D)$ dengan model pengembangan ADDIE yang terdiri lima tahap, yaitu Analysis, Design, Development Implementation and Evaluation . Pada tahap analisis dilakukan studi literature dan studi lapangan, kemudian memproduksi media dengan membuat flowchart, dan storyboard, kemudian membuat media tersebut sesuai dengan desain yang telah dibuat. Tahap akhir ialah evaluasi dimana media divalidasi oleh guru mata pelajaran sebagai ahli materi dan 3 orang ahli validasi media untuk melihat kelayakan media serta membuat laporan.

Hasil Penelitian dan Pengembangan media pembelajaran ini dikembangkan dengan model pengembangan ADDIE (Planning,Production, and Evaluation) dengan teknik pengumpulan data studi lapangan, studi literature dan angket yang dianalisis secara deskriptif oleh para ahli media dinyatakan bahwa media pembelajaran desktop ini "Sangat Layak" untuk di gunakan dengan persentase kelayakan 90\% dan presentase 91\% oleh ahli materi dinyatakan "sangat layak".
\end{abstract}

Kata kunci : Media Pembelajaran , ADDIE, Operasi Hitung Aljabar, Matematika

\section{Pendahuluan}

Pada era sekarang ini, perkembangan dibidang teknologi komunikasi dan informasi sangat pesat. Perkembangan teknologi informasi dan komunikasi telah mendorong lahirnya inovasi-inovasi baru disegala bidang kehidupan seperti bidang pendidikan. Kemajuan teknologi informasi dan komunikasi dalam bidang pendidikan pada penggunaan alat media pembelajaran yang berkonsep electronic learning $(e-$ learning). E-learning adalah pembelajaran yang disusun dengan tujuan menggunakan sistem elektronik atau komputer sehingga mampu mendukung proses pembelajaran. Pembelajaran menggunakan e-learning mempermudah siswa dalam proses belajar karena dapat dilakukan kapan saja dan dimana saja. Dengan demikian, teknologi mendorong terjadinya evolusi pada lokasi dan waktu belajar. Siswa sebagai inti dari proses belajar mengajar, harus dilibatkan dalam semua fase pembelajaran, dan merupakan tugas seorang guru untuk menjadikan siswa lebih aktif serta memberikan pengalaman belajar yang dinamis dan bermakna $[1,2]$.

Perkembangan ilmu pengetahuan dan teknologi semakin mendorong upaya-upaya pembaharuan dalam pemanfaatan hasil teknologi dalam proses belajar. Para guru dituntut agar mampu menggunakan alat-alat yang disediakan oleh sekolah. Di samping mampu menggunakan alat-alat yang tersedia, guru juga dituntut untuk dapat mengembangkan keterampilan membuat media pembelajaran yang akan digunakannya apabila media tersebut belum tersedia $[3,4,5]$.

Penggunaan teknologi komputer di SMP Negeri 22 Samarinda kurang maksimal bahkan untuk siswa kelas VII tidak menggunakan media komputer dalam proses pembelajarannya, khususnya pada mata pelajaran matematika. Mata pelajaran matematika termasuk dalam mata pelajaran sulit sehingga dibutuhkannya peranan teknologi dalam mempermudah penyampaian materi tersebut, sehingga materi yang disampaikan mudah diterima oleh siswa. Penyebab kurangnya pemahaman siswa dalam materi matematika adalah kesulitan siswa dalam memahami materi yang terdapat dalam buku paket yang tidak dijelaskan secara rinci dan kurangnya sumber belajar siswa [6]. salah satu materi yang sulit di pahami siswa materi operasi pada bentuk aljabar dalam 
penerapannya dikehidupan sehari-hari, dan kesulitan siswa dalam mengidentifikasi proses penyelesaian dari permasalahan tersebut yang diajarkan di kelas VII pada semester I.

Aljabar adalah bagian ilmu matematika dimana huruf dan simbol digunakan untuk mewakili bilangan dalam sebuah rumus atau persamaan. Untuk belajar aljabar, siswa harus memiliki suatu pemahaman konseptual tentang penggunaan simbolsimbol dan konteks dimana simbol-simbol tersebut digunakan. Pemahaman siswa terhadap simbol-simbol yang tepat dapat membantu siswa dalam mempelajari aljabar dengan mudah, namun banyaknya simbolsimbol operasi aljabar yang digunakan seringkali menyulitkan siswa dalam memahami bentuk aljabar $[7,8]$.

Untuk memudahkan siswa terhadap materi operasi hitung aljabar maka perlu dikembangkan sebuah media pembelajaran pada mata pelajaran matematika dengan menggunakan aplikasi Power Point. Dalam proses pembelajaran, guru dan siswa sudah tidak asing lagi dengan media pembelajaran yang bernama Power Point. Power Point menyediakan berbagai macam fitur yang dapat digunakan pengguna dalam memvariasikan tampilan presentasinya, seperti adanya transisi, animasi dan hyperlink. Selain dapat membuat tampilan lebih menarik, banyak juga para guru dan siswa tidak mengetahui bahwa dengan menggunakan Power Point, pengguna dapat membuat evaluasi pembelajaran bahkan dapat menampilkan skor jika diperlukan. Fitur tersebut dapat dibuat dengan menggunakan VBA (Visual Basic for Application).

VBA itu sendiri merupakan turunan dari bahasa pemrograman visual basic milik Microsoft. Selain menggunakan power point VBA juga menggunakan aplikasi Sparkol Videoscribe sebagai penjelasan materi berupa video pembelajaran. Sparkol videoscribe merupakan whiteboard animation video atau biasa disebut dengan whiteboard animation (animasi papan tulis). Penggunaan aplikasi ini untuk mempermudah siswa untuk memahami materi dan juga mengingat materi yang akan disampaikan karena Sparkol Videoscribe ini berfungsi menjelaskan tahaptahap dalam proses pengerjaan suatu materi dalam bentuk video.

Pada saat melakukan wawancara terhadap guru mata pelajaran matematika kelas VII di SMP Negeri 22 Samarinda diketahui bahwa proses pembelajaran pada mata pelajaran matematika masih menggunakan metode belajar ceramah dan belum memanfaatkan media pembelajaran elektronik. Kurang efektifnya penggunaan metode ceramah dan media pembelajaran tersebut dapat dilihat dari ratarata nilai kelas pada mata pelajaran matematika yang tidak memenuhi kriteria ketuntasan minimal yaitu 75 . Penggunaan media komputer hanya digunakan untuk pembelajaran tertentu di kelas IX. Tidak hanya itu dikarenakan juga nilai kebanyakan siswa yang selalu dibawah KKM. Peneliti juga melakukan observasi di kelas VII dengan jumlah 36 siswa dimana diketahui bahwa terdapat 30 siswa tidak menyukai dan 6 siswa menyukai pelajaran matematika dikarenakan mata pelajaran tersebut terbilang sebagai mata pelajaran yang sulit dimengerti, membingungkan dan membosankan bagi siswa.

Hal ini menyebabkan siswa seringkali tidak fokus pada penyampaian materi yang diberikan dan berpengaruh terhadap minat belajar siswa serta akan berdampak terhadap prestasi siswa di dalam sekolah maupun di luar sekolah. Melihat permasalahan ini dianggap perlu adanya pengembangan media pembelajaran alternatif yang dapat menunjang dan meningkatkan minat siswa dalam mempelajari mata pelajaran matematika.

\section{Metode Penelitian}

Jenis penelitian yang digunakan adalah R\&D (Research and Development). Research and Development ialah metode penelitian yang digunakan untuk menghasilkan produk tertentu dan menguji keefektifan produk tersebut. Untuk mendapatkan hasil produk tertentu, maka digunakan penelitian yang bersifat analisis kebutuhan dan untuk menguji kefektifan produk tersebut supaya dapat berfungsi pada masyarakat luas [9]

Prosedur penelitian ini menggunakan model pengembangan ADDIE. mengembangkan Instructional Design (Desain Pembelajaran) dengan pendekatan ADDIE, yang merupakan kepanjangan dari Analysis, Design, Development, Implementation and Evaluations. Subjek penelitian adalah siswa, ahli materi dan ahli validasi media dan Objek penelitian adalah media pembelajaran Matematika materi operasi hitung aljabar [10]

Teknis analisis data menggunakan Skala Likert, yaitu merubah data kualitatif menjadi kuantitatif dengan ketentuan skor dapat dilihat pada tabel 1 berikut [11]:

Tabel 1. Tabel Skor

\begin{tabular}{|c|c|}
\hline Skor & Kategori \\
\hline $\mathbf{5}$ & Sangat Layak \\
\hline $\mathbf{4}$ & Layak \\
\hline $\mathbf{3}$ & Cukup Layak \\
\hline $\mathbf{2}$ & Tidak Layak \\
\hline $\mathbf{1}$ & Sangat tidak Layak \\
\hline
\end{tabular}

Untuk menghitung rata-rata skor tiap aspek penilaian ahli materi dan ahli media digunakan rumus :

Keterangan :

$$
\operatorname{Mean}(\bar{x})=\frac{\sum x}{N}
$$

$$
\begin{array}{ll}
\bar{x} & : \text { Skor rata-rata } \\
\sum x & : \text { Jumlah Total Skor } \\
N & :(\text { Indikator } \times \text { Responden) }
\end{array}
$$

Untuk mengintrepretasikan secara kualitatif jumlah rerata skor tiap aspek dengan menggunakan kriteria. Berikut acuan kriteria konversi skor : 


Tabel 2. Rumus Konversi Jumlah Rerata Skor
\begin{tabular}{|c|c|c|}
\hline Nilai & Skor & Kategori \\
\hline $\mathbf{5}$ & $x>x i+1,80 \mathrm{Sb} i$ & Sangat Layak \\
\hline $\mathbf{4}$ & $x i+0,60 \mathrm{SBi}<x \leq x i+1,80 \mathrm{Sb} i$ & Layak \\
\hline $\mathbf{3}$ & $x i-0,60 \mathrm{SBi}<x \leq x i+$ & Cukup Layak \\
& $0,60 \mathrm{SB} i$ & Tidak Layak \\
\hline $\mathbf{2}$ & $x i-1,80 \mathrm{SBi}<x \leq x i-0,60 \mathrm{SB} i$ & $\begin{array}{c}\text { Sangat Tidak } \\
\text { Layak }\end{array}$ \\
\hline $\mathbf{1}$ & $x \leq x i-1,80 \mathrm{Sbi}$ & \\
\hline
\end{tabular}

Keterangan :

$$
\begin{aligned}
& x=\text { Skor Empiris / Sebenarnya } \\
& x i=\text { Rata-rata Ideal } \\
& =\frac{1}{2}(\text { Skor maksimal }+ \text { Skor minimal }) \\
& \mathrm{SB} i=\text { Simpangan baku ideal } \\
& =\frac{1}{6}(\text { skor maksimal }- \text { skor minimal })
\end{aligned}
$$

Sedangkan rumus untuk mengitung persentase rerata penilaian dari ahli materi dan ahli media digunakan rumus sebagai berikut:

$$
\begin{aligned}
x i= & \frac{\sum S}{\text { Smax }} \times 100 \% \\
\text { Ket }: & \\
\operatorname{Smax} & =\text { Skor Maksimal } \\
\sum_{\mathrm{x} i} \quad & =\text { Jumlah Skor } \\
& =\text { Nilai kelayakan angket tiap aspek }
\end{aligned}
$$

Hasil skor persentase yang diperoleh dari penelitian diinterpresentasikan dalam kriteria tabel berikut :

Tabel 3. Skala Kelayakan Media Pembelajaran

\begin{tabular}{|l|l|}
\hline \multicolumn{1}{|c|}{ Presentase } & \multicolumn{1}{c|}{ Kriteria } \\
\hline $\mathrm{x}>81 \%$ & Sangat Layak \\
\hline $61 \%<\mathrm{x} \leq 80 \%$ & Layak \\
\hline $41 \%<\mathrm{x} \leq 60 \%$ & Cukup Layak \\
\hline $21 \%<\mathrm{x} \leq 40 \%$ & Kurang Layak \\
\hline $\mathrm{x} \leq 20 \%$ & Sangat Kurang Layak \\
\hline
\end{tabular}

\section{Hasil Dan Pembahasan}

\subsection{Hasil}

Penelitian dan pengembangan ini dilakukan secara online (Via Zoom cloud meeting, email, google drive) dan di SMPN 22 Samarinda yang beralamat di jalan Pahlawan NO.36, Dadi Mulya, Kec. Samarinda Ulu, Kota Samarinda, Kalimantan Timur 75123.

Penelitian ini di laksanakan pada bulan November 2020 semester ganjil tahun ajaran 2020/2021 dengan Ahli Materi, dan Ahli Media.

Tahap pertama dimulai dengan melakukan analisis yaitu studi lapangan dan studi literatur. Studi lapangan dilakukan dengan mewawancara langsung kepada guru pengampuh mata pelajaran yaitu $\mathrm{Bu}$ Titin Suhartini S.Pd. Pada analsis kurikulum diperoleh bahwa kurikulum yang digunakan di SMP Negeri 22 Samarinda adalah kurikulum 2013 dan pelajaran TIK masih tetap ada namun dijadikan muatan lokal. Analisis mata pelajaran dan silabus digunakan untuk membantu pengarahan dalam pembuatan media pembelajaran agar sesuai tujuan yang ingin di capai. Studi lapangan dilakukan dengan langsung melihat kondisi laboratorium dan melakukan wawancara terhadap guru TIK SMP Negeri 22 Samarinda, yaitu
Bapak Mi'in, S.Psi. Sedangkan studi literatur dilakukan dengan mencari referensi penelitian yang relevan dengan penelitian yang akan dilakukan.

Tahap kedua adalah perancangan. Tahap perencanaan dimulai dari perancangan flowchart, perancangan storyboard, penyusunan materi, penyusunan instrumen penilaian dan pengumpulan bahan pendukung.

Tahap ketiga ialah tahap pengembangan dimana pada tahap ini peneliti membuat media pembelajaran sesuai dengan perencanaan yang telah dibuat sebelumnya. Pada proses pengembangan, peneliti menggunakan Ms. Power Point dan VBA dalam pembuatan aplikasi. Aplkasi tersebut berisi materi, video pebelajaran dan beberapa soal. Setelah aplikasi rampung, selanjutnya ialah melakukan validasi oleh ahli media dan ahli materi. Validasi ahli media mencakup aspek bahasa, aspek rekayasa perangkat dan aspek komunikasi visual. Hasil perolehan penilaian kelayakan oleh ahli media ialah 63 yang termasuk kategori "Sangat Layak" dengan presentase kelayakan 90\%. Sedangkan validasi ahli materi mencakup aspek relevensi materi, aspek evaluasi, aspek efek untuk strategi pembelajaran den dan aspek bahasa. Hasil perolehan penilaian kelayakan oleh ahli materi ialah 91 yang termasuk kategori "Sangat Layak" dengan presentase kelayaan 91\%.

Tahap keempat ialah tahap implementasi. Pada tahap ini aplikasi yang telah diperbaiki sesuai saran ahli media dan ahli materi sebelum di uji cobakan pada peserta didik. Ada dua tahap uji coba, yaitu uji coba kelompok kecil dan uji coba lapangan. Uji coba terhadap peserta didik mencakup aspek motivasi belajar, aspek kemudahan pemakaian, aspek kemenarikan tampilan dan aspek kebermanfaatan aplikasi. Hasil perolehan penilaian kelayakan pada uji coba kelompok kecil ialah 39,6 yang termasuk kategori "Layak". Hasil penilaian kelayakan pada uji coba lapangan ialah 41 yang termasuk kategori "Layak".

Tahap kelima ialah tahap evaluasi. Pada tahap ini dilakukan pengelolaan terhadap hasil penilaian dan penarikan kesimpulan. Berdasarkan hasil perolehan angket dari ahli media, ahli materi dan siswa, maka dapat disumpulkan bahwa media pembelajaran berbasis desktop pada pokok bahasan operasi hitung aljabar ini dinyatakan layak untuk di gunakan.

\subsection{Pembahasan}

Tahap pertama dimulai dengan melakukan analisis yaitu studi lapangan dan studi literatur. Studi lapangan dilakukan dengan mewawancara langsung kepada guru pengampuh mata pelajaran yaitu Bu Titin Suhartini S.Pd. Pada analsis kurikulum diperoleh bahwa kurikulum yang digunakan di SMP Negeri 22 Samarinda adalah kurikulum 2013 dan pelajaran TIK masih tetap ada namun dijadikan muatan lokal. Analisis mata pelajaran dan silabus digunakan untuk membantu pengarahan dalam pembuatan media pembelajaran agar sesuai tujuan yang ingin di capai. 
Studi lapangan dilakukan dengan langsung melihat kondisi laboratorium dan melakukan wawancara terhadap guru TIK SMP Negeri 22 Samarinda, yaitu Bapak Mi'in, S.Psi. Sedangkan studi literatur dilakukan dengan mencari referensi penelitian yang relevan dengan penelitian yang akan dilakukan.

Tahap kedua adalah perancangan. Tahap perencanaan dimulai dari perancangan flowchart, perancangan storyboard, penyusunan materi, penyusunan instrumen penilaian dan pengumpulan bahan pendukung.

Tahap ketiga ialah tahap pengembangan dimana pada tahap ini peneliti membuat media pembelajaran sesuai dengan perencanaan yang telah dibuat sebelumnya. Pada proses pengembangan, peneliti menggunakan Ms. Power Point dan VBA dalam pembuatan aplikasi. Aplkasi tersebut berisi materi, video pebelajaran dan beberapa soal. Setelah aplikasi rampung, selanjutnya ialah melakukan validasi oleh ahli media dan ahli materi. Validasi ahli media mencakup aspek bahasa, aspek rekayasa perangkat dan aspek komunikasi visual. Hasil perolehan penilaian kelayakan oleh ahli media ialah 63 yang termasuk kategori "Sangat Layak" dengan presentase kelayakan 90\%. Sedangkan validasi ahli materi mencakup aspek relevensi materi, aspek evaluasi, aspek efek untuk strategi pembelajaran den dan aspek bahasa. Hasil perolehan penilaian kelayakan oleh ahli materi ialah 91 yang termasuk kategori "Sangat Layak" dengan presentase kelayaan 91\%.

Tahap keempat ialah tahap implementasi. Pada tahap ini aplikasi yang telah diperbaiki sesuai saran ahli media dan ahli materi sebelum di uji cobakan pada peserta didik. Ada dua tahap uji coba, yaitu uji coba kelompok kecil dan uji coba lapangan. Uji coba terhadap peserta didik mencakup aspek motivasi belajar, aspek kemudahan pemakaian, aspek kemenarikan tampilan dan aspek kebermanfaatan aplikasi. Hasil perolehan penilaian kelayakan pada uji coba kelompok kecil ialah 39,6 yang termasuk kategori "Layak". Hasil penilaian kelayakan pada uji coba lapangan ialah 41 yang termasuk kategori "Layak".

Tahap kelima ialah tahap evaluasi. Pada tahap ini dilakukan pengelolaan terhadap hasil penilaian dan penarikan kesimpulan. Berdasarkan hasil perolehan angket dari ahli media, ahli materi dan siswa, maka dapat disumpulkan bahwa media pembelajaran berbasis desktop pada pokok bahasan operasi hitung aljabar ini dinyatakan layak untuk di gunakan.

\section{Kesimpulan}

Berdasarkan hasil penelitian dan pengembangan yang telah dilakukan, maka peneliti menyimpulkan bahwa Media pembelajaran berbasis desktop dikembangkan dengan menggunakan PPT VBA dan Parkol Videoscribe dengan model pengembangan ADDIE yaitu Analysis, design, development, implementation and evaluation. Tahap awal yaitu analisis kebutuhan yang menjadi standar dalam pembuatan media, kemudian mendesain media dengan membuat storyboard. Setelah itu, membuat media dan dievaluasi oleh ahli media dan ahli materi untuk menguji kelayakan media. Tahap selanjutnya melakukan perbaikan media hasil dari evaluasi ahli media dan materi dimana akan diperoleh informasi kelayakan media serta melakukan pelaporan. Menurut ahli media, media pembelajaran berbasis desktop pada pokok bahasa operasi hitung aljabar "Sangat Layak" digunakan dengan persentase kelayakan 90\% dan menurut ahli materi "Sangat Layak" dengan presentase kelayakan $91 \%$.

\section{Daftar Rujukan}

[1] Al-Munawwaroh, Rofiqah. 2019. Sparkol Videoscribe Sebagai Media Pembelajaran. Skripi S1 Tarbiyah dan Keguruan, Universitas Islam Negeri Alauddin Makassar.

[2] Rachmawati, Tutik dan Daryanto. 2015. Teori Belajar dan Proses Pembelajaran yang Mendidik. Yogyakarta: Penerbit Gava Media.

[3] Ariani, Niken dan Dany Haryanto. 2010. Pembelajaran Multimedia di Sekolah Pedoman Pembelajaran Inspiratif, konstruktif, dan prospektif. Jakarta: Prestasi Pustaka.

[4] Arsyad, Azhar. 2016. Media Pembelajaran Edisi Revisi. Jakarta: PT Rajagrafindo Persada.

[5] Budiningsih, Asri. 2012. Belajar \& Pembelajaran. Jakarta: PT Rineka Cipta.

[6] Sutikno, Sobry. 2013. Belajar dan Pembelajran "Upaya Kreatif dalam mewujudkan Pembelajaran yang Berhasil”. Lombok: Holistica

[7] As'ari, Abdur Rahman. dkk. 2017. Matematika SMP Kelas VII Semester I. Jakarta: Kemendikbud.

[8] Sundayana, Rostina. 2013. Media Pembelajaran Matematika. Bandung: Alfabeta.

[9] Sugiyono. 2019. Metode Penelitian dan Pengembangan Research dan Development. Bandung: Alfabeta

[10] Azwar, Saifuddin. 2014. Metode Penelitian. Yogyakarta: Pustaka Pelajar.

[11] Emzir. 2013. Metodologi Penelitian Pendidikan: Kuantitatif dan Kualitatif. Jakarta: PT Raja Grafindo Persada. 